\title{
Effectiveness of Social Skill Training Programme on Social Anxiety and Self-Esteem among Adolescents
}

\author{
Vidyanand Kasappa Shitavvagol ${ }^{1}$, Shriharsha $C^{2}$, Deelip S. Natekar ${ }^{3}$ \\ ${ }^{1}$ M.Sc. Nursing 2nd Year Student, Department of Psychiatric Nursing, BVVS Sajjalashree Institute of Nursing \\ Sciences, Navanagar, Bagalkot - 587103, Karnataka, India. \\ ${ }^{2}$ Professor \& HOD, Department of Psychiatric Nursing, BVVS Sajjalashree Institute of Nursing Sciences, \\ Navanagar, Bagalkot - 587103, Karnataka, India. \\ ${ }^{3}$ Principal, BVVS Sajjalashree Institute of Nursing Sciences, Navanagar, Bagalkot -587103 , Karnataka, India. \\ Corresponding Author: Shriharsha C
}

DOI: https://doi.org/10.52403/ijshr.20220107

\begin{abstract}
Background: Social skill training is one of the most effective managements for the client with social anxiety and self-esteem. Hence the investigator felt the need to evaluate the effectiveness of social skill training programme on social anxiety and self-esteem.
\end{abstract}

Aim: to assess the effectiveness of social skill training program on social anxiety and selfesteem among adolescents studying in selected high schools of Bagalkot."

Methodology: True experimental study with pre test- post test control group design with 100 subjects selected through simple random sampling technique and assigned 50 adolescents to experimental group and 50 adolescents to control group by using computer generated random numbers. Data was collected using Kutcher Generalized Social Anxiety Disorder scale to assess the social anxiety and Rosenberg Self-esteem Scale to assess the self-esteem among adolescents. Social skill training program was administered for $45 \mathrm{mins}$ to 1 hour for 6 consecutive days for experimental group. Data were analyzed by using descriptive and inferential statistics in terms of frequency distribution, percentage, mean, mean percentage, Standard Deviation, paired' $t$ ' test, Unpaired ' $t$ ' test and Chi-square test.

Findings: Findings related to significance of difference between post test social anxiety and self-esteem scores of experimental group and control group subjects revealed that, a statistically significant difference was found between post test social anxiety scores of experimental group and control group subjects $[t=7.23), \quad p<0.05]$.Similarly there was a statistically significant difference found between post-test self-esteem scores of experimental group and control group subjects $[\mathrm{t}=6.71$, $\mathrm{p}<0.05]$.

Conclusion: The study proved that Social skill training programme on social anxiety and selfesteem among adolescents was effective, scientific, logical and cost effective strategy.

Keywords: Adolescents, Social anxiety, Selfesteem, Effectiveness, Social skill training programme and Socio-demographic variables.

\section{INTRODUCTION}

Adolescence is a transitional stage in physical and psychological development that is generally confined to the period from puberty to legal adulthood. It is also a period of multiple transitions involving education, training, employment and unemployment, as well as transitions from one living circumstance to another. ${ }^{1}$

Social anxiety is an significant discomfort and avoidance of social and/or performance situationsis among the most common mental disorders in children and adolescents. Recent estimates indicate that 4 $\%$ of children and $22.1 \%$ of adolescents meet criteria for this diagnosis. Social anxiety disorder starts as early as age 7 and peaks around age 16. When untreated, it 
runs a chronic course into adolescence and eventually adulthood. ${ }^{2}$

Social anxiety is marked or intense fear of social situations in which the individual may be scrutinized by others and this situation interferes significantly with routines and social anxiety may cause disturbance in occupational (academic) functioning, social activities, and relationships. ${ }^{3}$

In India, adolescents (10-19 years) constitute $21.4 \%$ or one-fifth of the total population. However, there are only a few studies about adolescent psychosocial problems from India. Most of the epidemiological surveys on school going children and adolescents have reported a wide variation $(20 \%-33 \%)$ in the prevalence of psychosocial problems. An epidemiological study by the Indian Council of Medical Research showed the prevalence rates of child and adolescent psychiatric disorders to be $12.5 \%$ in children aged $0-16$ years. A meta-analysis of psychiatric morbidity among child and adolescents found the prevalence of $6.4 \%$ psychiatric disorders in community samples and $23.33 \%$ in school samples. Hence, there is an urgent need to develop mental health resources for children and adolescents in India. ${ }^{4}$

Self-esteem is the subjective perception about one's own self, body, mental functioning, social attitudes and adjustment in various aspects of life, plays a huge role in overall mental health and wellbeing. It influences one's capacity to control impulses, the relationship with one's own body, relationships with family and friends, ability to cope with problems, sexual attitudes, and so on. A negative self-image could significantly increase the likelihood of social anxiety in adolescents. ${ }^{5}$

Social skill training plays vital role to reduce the social anxiety disorder (SAD) among children and adolescents. Empirical evidence shows that cognitive behavioral therapy (CBT) has been shown to be efficacious for SAD and is considered the first-choice psychological intervention for the social anxiety disorder. However, despite the good results, there is general agreement on the need to improve the range of effectiveness and efficiency of this treatments. ${ }^{6}$

A study was conducted in Clark Atlanta University on the effects of social skills training as an intervention program on maltreated children. The results indicated a decrease in the severity level of self-esteem deficit, an increase in self-esteem and overall behavior. The results are promising evidence on the impact of social skills training programs and promotes the use of social skills training as an intervention method with maltreated children. ${ }^{7}$

After going through an extensive literature, it is clear that, Social anxiety very common among adolescents and social anxiety reduces the self-esteem of adolescents. Hence, Researcher has planned to undertaken "a study to assess the effectiveness of social skill training program on social anxiety and self-esteem among Adolescents studying in selected High Schools of Bagalkot.

\section{MATERIAL AND METHODS Study Design and Participants}

Present study was a Trueexperimental pre-test-post-test control group design conducted between 3 Feb 2020 to 8 Feb 2020 A Simple random sampling technique was used to select the 50 subjects to experimental group and 50 subjects to control group for the present study. Study was conducted in selected high schools of Bagalkot. Who are with mild to moderate social anxiety, with low self-esteem and in the age group of 13-19 yrs.

\section{Instruments \\ Kutcher generalized social anxiety disorder scale:}

Kutcher generalized social anxiety disorder scale was developed by Kutcher. Kutcher generalized social anxiety disorder scale (K-GSADS-A) to assess the social anxiety among adolescents which consists of 18 items. Response options range from 0 
to 3 for each item $(0=$ Never. $1=$ Mild, $2=$ Moderate, $3=$ Severe/ Total avoidance). Thus, total score for assessing social anxiety scale ranges from $0-54$ for 18 items. Range of score: Score ranging from $0-18$ will be considered mild social anxiety, Score ranging from 19-36 will be considered moderate social anxiety and score ranging from 37-54 will be considered severe/total avoidance. For the present study reliability for the Kutcher generalized social anxiety disorder scale for adolescents was established by test retest method and obtained score was 0.93 .

\section{Rosenberg's self esteem scale:}

Rosenberg's self esteem scale was developed by Rosenberg and was used to screen for low self esteem among adolescents. There are 10 items in Rosenberg's self esteem inventory scale. There are 5 items for assessing positive self esteem $(1,3,4,7,10)$ scoring of these items range from 3 to 0 ( $3=$ Strongly agree, $2=$ Agree, $1=$ Disagree $.0=$ Strongly disagree $)$. There are 5 items for assessing negative self esteem $(2,5,6,8,9$ scoring of these items range from 0 to $3(0=$ Strongly agree, $1=$ Agree, $2=$ Disagree, $3=$ Strongly disagree) Thus, total score for assessing self esteem range from 0-30 for 10 items. Range of score: Score ranging from $0-15$ will be considered low self-esteem. Score ranging from 16-30 will be considered normal self esteem. For the present study reliability for the Rosenberg's self esteem scale for adolescents was established by test retest method and obtained score was 0.87 .

\section{Socio-demographic Variables and Clinical characteristics}

Socio-Demographic characteristics of adolescents such as age, sex, religion, year of study, father educational status, mother educational status, father's occupation, mother's occupation, number of siblings, area of residence, type of family monthly family income, birth order.

\section{Data Collection Procedures}

Prior permission was taken from the Principal of the Sajjalashree institute of Nursing sciences, Bagalkot \& the Head master of selected high schools of Bagalkot and informed consent from the subjects.

Pre-test conducted to assess the social anxiety and self esteem among adolescents of experimental group and control group followed by administration of Social skill training i.e, psychosocial intervention which includes training of effective communication skills, positive assertive behavior, self-esteem boosting activities and training of essential social skills like eye contact with others during conversation, smiling when greeting people, shaking hands when meeting someone, using the right tone and volume of the voice, expressing opinion to others, appropriate emotional responses etc. The interventions will be administered in six sessions on daily bases and each session will last for $45 \mathrm{mins}$ to 1 hour. On $6^{\text {th }}$ day immediate post intervention assessment of social anxiety and self-esteem among adolescents of both experimental group and control group.

\section{Data Analysis}

Descriptive statistics (Frequency distribution, percentage, mean and standard deviation and mean percentage) and inferential statistics (Paired ' $t$ ' test, Unpaired ' $t$ ' test, Chi square test) were used for analysis and interpretation of data.

\section{RESULTS \\ Descriptive analysis of sample characteristics}

Percentagewise distribution of adolescents according to their age group reveals that majority of the adolescents (32\%) in experimental group were in the age group of 17-18 yrs Similarly, in control group, majority of the adolescents (32\%) were in the age group of 13-14 yrs and again 32 percent of them were in the age of 17-18 yrs. Majority of the adolescents $(64 \%)$ in experimental group and in control 
Vidyanand Kasappa Shitavvagol et.al. Effectiveness of social skill training programme on social anxiety and self-esteem among adolescents.

group $(72 \%)$ were males. Majority of the adolescents $(72 \%)$ in experimental group and in control group (76\%) were Hindu. Percentage wise distribution of adolescents according to their father's educational status illustrates that higher percentage of the adolescent fathers $(52 \%)$ in experimental group in experimental group were illiterates and $28 \%$ in primary education and in control group, most of the adolescents father's educational status were illustrates that higher percentage of the adolescent fathers $(50 \%)$ were illiterates and followed by $36 \%$ in primary education. Majority of the adolescent father's occupation were in experimental group (38\%) and of control group were labour worker $(46 \%)$. Majority of the adolescent mother's occupation were in experimental group (44\%) and of control group were housewife (44\%). Majority of the adolescents $(38 \%)$ in experiment group were studying in $10^{\text {th }}$ std where as in control group, most of the adolescents $(34 \%)$ were from $8^{\text {th }}$ std and another $34 \%$ were from $9^{\text {th }}$ std. Majority of the adolescents (44\%) were in experimental group of had their family monthly income is ranging between 10, 00120,000 in control group also the higher of the adolescent's family monthly income. (42\%) ranging between Rs 10,001-20,000. Majority of the adolescents in experimental group (62\%) and in control group (66\%) were belonging to the in urban area. Majority of the adolscent according to their type of family ( $74 \%$ ) in experimental group were belonging to nuclear family and control group were also belonging to nuclear family $(76 \%)$. Majority of the adolescents in experimental group (50\%) and of control group (52\%) had two siblings. Majority (46\%) of the adolescents' birth order in both experimental group and control group was second.

\section{Description of Assessment of pretest scores of social anxiety and self esteem among adolescents.}

Table: 1- Level of social anxiety among adolescents in pre test. $\quad n=50+50=100$

\begin{tabular}{|l|l|l|l|l|l|}
\hline \multicolumn{2}{|l|}{ LEVELS OF SOCIAL ANXIETY } & \multicolumn{2}{|l|}{ EXPERIMENTAL GROUP } & \multicolumn{2}{l|}{ CONTROL GROUP } \\
\hline & Range of Score & Frequency & Percentage & Frequency & Percentage \\
\hline Mild social anxiety & $0-18$ & 25 & $50 \%$ & 28 & $56 \%$ \\
\hline Moderate social anxiety & $19-36$ & 25 & $50 \%$ & 22 & $44 \%$ \\
\hline
\end{tabular}

Table 1 show that majority of the adolescents of both experimental group (50\%) and control group (56\%) had mild social anxiety

Table: 2- Level of self esteem among adolescents in pre test. $\mathrm{n}=\mathbf{5 0 + 5 0 = 1 0 0}$

\begin{tabular}{|l|l|l|l|l|l|}
\hline LEVEL OF SELFESTEEM & EXPERIMENTAL GROUP & \multicolumn{2}{|c|}{ CONTROL GROUP } \\
\hline Levels & Range of Score & F & \% & F & \% \\
\hline Low self esteem & $0-15$ & 41 & $82 \%$ & 44 & $88 \%$ \\
\hline Normal self esteem & $16-30$ & 9 & $18 \%$ & 6 & $12 \%$ \\
\hline
\end{tabular}

Table 2 shows that the majority of adolescents of both experimental group (82\%)) and control group (88\%) had low self esteem.

\section{Effectiveness of social skill training programme on social anxiety and self-esteem of adolescents.}

Table: 3- Significance of the difference in post-test scores of social anxiety and self esteem between adolescents of experimental and control group. $\mathbf{n}=\mathbf{5 0 + 5 0 = 1 0 0}$

\begin{tabular}{|l|l|l|l|l|c|}
\hline Variables & Group & SD of post-test scores & Mean difference & 't' value (unpaired) & 'p' value \\
\hline \multirow{2}{*}{ Social anxiety } & Experimental group & 5.004 & -7.84 & -6.86 & $0.000^{* * *}$ \\
\cline { 2 - 5 } & Control group & 6.34 & 8.60 & & $0.000^{* * *}$ \\
\hline \multirow{2}{*}{ Self esteem } & Experimental group & 4.91 & & 8.48 & \\
\cline { 2 - 3 } & Control group & 5.21 & & & \\
\hline
\end{tabular}

Hence it is concluded that there was a statistically significant difference found between post-test self esteem scores between experimental group and control group adolescents. Hence it is concluded that social skill training is an effective tool 
Vidyanand Kasappa Shitavvagol et.al. Effectiveness of social skill training programme on social anxiety and self-esteem among adolescents.

to reduce social anxiety and to improve self esteem of adolescents.

Association between the pre-test social anxiety and self esteem scores of adolescents and socio-demographic variables of adolescents.

Table: 4- Association between the pre-test social anxiety scores of adolescents and their socio-demographic variables of both experimental group and control group. $n=50+50=100$

\begin{tabular}{|c|c|c|c|c|}
\hline Sl.no & $\begin{array}{l}\text { Socio-demographic } \\
\text { variables }\end{array}$ & DF & $\begin{array}{l}\text { Chi square } \\
\text { value }\left(\chi^{2}\right)\end{array}$ & $\begin{array}{l}\text { 'P' } \\
\text { value }\end{array}$ \\
\hline 1 & Age & 3 & 1.23 & 0.75 \\
\hline 2 & Sex & 1 & 0.17 & 0.83 \\
\hline 3 & Religion & 2 & 8.89 & 0.41 \\
\hline 4 & $\begin{array}{l}\text { Education status of } \\
\text { father }\end{array}$ & 3 & 3.08 & 0.38 \\
\hline 5 & $\begin{array}{l}\begin{array}{l}\text { Education status of } \\
\text { mother }\end{array} \\
\end{array}$ & 3 & 2.59 & 0.47 \\
\hline 6 & Occupation of father & 3 & 0.84 & 0.85 \\
\hline 7 & Occupation of mother & 3 & 4.83 & 0.19 \\
\hline 8 & Year of study & 2 & 2.63 & 0.27 \\
\hline 9 & Family monthly income & 2 & 0.17 & 0.93 \\
\hline 10 & Area of residence & 1 & 1.65 & 0.21 \\
\hline 11 & Type of family & 1 & 0.33 & 0.56 \\
\hline 12 & Number of siblings & 2 & 3.32 & 0.18 \\
\hline 13 & Birth order & 3 & 2.49 & 0.57 \\
\hline
\end{tabular}

$$
P<0.05 \text { [Significant] }
$$

Findings related to the association between pre-test social anxiety scores of adolescents with their selected sociodemographic variables reveals that, there was no significant association was found between social anxiety scores of adolescents with any of their selected sociodemographic variables.

Table: 5- Association between the pre-test self esteem scores of adolescents and their socio-demographic variables. $n=$ $\mathbf{5 0 + 5 0 = 1 0 0}$

\begin{tabular}{|c|c|c|c|c|}
\hline Sl.no & $\begin{array}{l}\text { Socio-demographic } \\
\text { variables }\end{array}$ & DF & $\begin{array}{l}\text { Chi square } \\
\text { value }\left(\chi^{2}\right)\end{array}$ & $\begin{array}{l}\text { 'P' } \\
\text { value }\end{array}$ \\
\hline 1 & Age & 3 & 0.25 & 0.97 \\
\hline 2 & Sex & 1 & 2.82 & 0.13 \\
\hline 3 & Religion & 2 & 8.89 & $0.017 *$ \\
\hline 4 & $\begin{array}{l}\text { Education status of } \\
\text { father }\end{array}$ & 3 & 1.99 & 0.60 \\
\hline 5 & $\begin{array}{l}\text { Education status of } \\
\text { mother }\end{array}$ & 3 & 0.83 & 0.82 \\
\hline 6 & Occupation of father & 3 & 2.00 & 0.59 \\
\hline 7 & Occupation of mother & 3 & 1.78 & 0.61 \\
\hline 8 & Year of study & 2 & 1.75 & 0.41 \\
\hline 9 & Family monthly income & 2 & 0.29 & 0.87 \\
\hline 10 & Area of residence & 1 & 0.54 & 1.00 \\
\hline 11 & Type of family & 1 & 3.16 & 0.10 \\
\hline 12 & Number of siblings & 2 & 0.43 & 0.83 \\
\hline 13 & Birth order & 3 & 11.08 & $0.029 *$ \\
\hline
\end{tabular}

Findings related to the association between pre-test self esteem scores of adolescents with their selected sociodemographic variables reveals that, significant association was found between self-esteem scores of adolescents with their religion $\quad(=8.89, \quad \mathrm{p}<0.05) \quad$ birth order $\left(\mathrm{x}^{2}=11.09, \quad \mathrm{p}<0.05\right) \quad$ socio-demographic variable and rejected for other socio demographic variables.

\section{DISCUSSION}

The main objective of the present study was to assess the effectiveness of social skill training program on social anxiety and self-esteem among adolescents studying in selected high schools of Bagalkot.

After reviewing many studies related to effectiveness of social skill training programme on social anxiety and selfesteem among adolescents has immensely influenced me to take up the present study, The studies influenced me to conduct this present study as follows.

A study was conducted to assess the effectiveness of social skill training on self esteem, adjustment and social anxiety among adolescents. Total sample comprised of 60 students (30 males and 30 females) from the Hans Raj Model School, Punjabi Bagh who has received social skill training from the team of Expressions India. Self esteem inventory (school form), Adjustment inventory for school students (AISS) were administered in a group session one by one in two or three days both before training was given and after training. In the post condition, test scores were obtained after 5 months of training. The result showed that subjects improved significantly in post condition on self-esteem, emotional adjustment, social anxiety. However, no significant difference was found on social adjustment in pre and post condition. Results concludes that overall training was very effective as subjects improved in the post condition on all measures, thus showing that social skill training do show positive result $\mathrm{s}$ in bringing change in adolescents. $^{8}$

A study was conducted to assess the effectiveness of a social skills training among adolescents on social skills, social 
Vidyanand Kasappa Shitavvagol et.al. Effectiveness of social skill training programme on social anxiety and self-esteem among adolescents.

anxiety and self-esteem. A group of 14- to 16-year-old normal adolescents followed a social skills training based on social learning principles. A pre-test experiment post-test design was used and the group's performance was compared with that of a non-intervention control-group. The training was given at school, and the data were collected by means of self-report measures. The results concludes that the training was successful in several respects and the adolescents with social anxiety is decreased and their social activity, self-esteem was improved. $^{9}$

\section{Recommendation}

A similar study can be undertaken with a large stratified sample including adolescents from different sections of society to generalize the findings. A study can be conducted to find out the prevalence of social anxiety and low self esteem among adolescents. A study can be carried out to evaluate the efficiency of various teaching strategies like SIM, pamphlets and computer-assisted instruction on of social anxiety and low self esteem among adolescents.

\section{CONCLUSIONS}

Finding reveals that the experimental group social anxiety and self-esteem scores and control group social anxiety and self-esteem has significant difference. Which shows that the decreased social anxiety and increased self-esteem in the adolescents. The study proved that social skill training programme on social anxiety and self-esteem among adolescents was effective, scientific, logical and cost-effective strategy.

\section{Ethical Clearance}

Ethical clearance was obtained from the institutional ethical committee of BVVS Sajjalashree Institute of Nursing Sciences, Bagalkot.

\section{Source of Funding: Self} Conflict of Interest: Nil

\section{Acknowledgement: None}

\section{REFERENCES}

1. Zaky EA.Adolescence; A crucial transitional stage in human life. J Child AdolescBehav 4. 2017;(3):2375-4494.

2. Mehtalia K, Vankar GK. Social anxiety among adolescents. Indian journal of Psychiatry. 2004;46(3):221-227.

3. Ryan JL, Warner CM, Treating Adolescents with Social Anxiety Disorder in Schools Journal of the child Adolescpsychitr Clin N Am.2012 21(1) Jan .

4. Mishra S, Srivastava M, Tiwary N. Prevalence of depression and anxiety among children in rural and suburban areas of Eastern Uttar Pradesh: A cross-sectional studyJ Family Med Prim Care. 2018 JanFeb; 7(1):21-26.

5. How self-image and social anxiety collide in teens. February 10 2016.Available from URL: https://www.anxiety.org/teens-socialanxiety-self-imag

6. Cunsic A. An Overview of Social Skills Training 2018. Available from URL: https://www.verywellmind.com

7. A study of the effects of social skills training on self-esteem of maltreated children. March3,2011. Available from URL:http://digitalcommons.auctr.edu/cgi/vi ewcontent .cgi article $=3486 \&$ context $=$ disser tations.

8. Yadav P, Jamia NI, Islamia M. Impact of social Skill Training on Self-esteem, Adjustment and social anxiety among Adolescents. Journal of the Indian Academy of Applied Psychology.October 2009; (35):61-70.

9. Bijstra J, Jackson S. Social skills training with early adolescents: Effects on social skills, social anxiety, well-being, selfesteem and coping. European Journal of Psychology of Education. 2017;13(2): 569583.

How to cite this article: Vidyanand Kasappa Shitavvagol, Shriharsha C, Natekar DS. Effectiveness of social skill training programme on social anxiety and self-esteem among adolescents. International Journal of Science \& Healthcare Research. 2022; 7(1): 35-40. DOI: https://doi.org/10.52403/ijshr.20220107 